\title{
MASCULINIDADES E A FORMAÇÃO DE PROFESSORES/AS DE EDUCAÇÃO FÍSICA NA EEFD/UFRJ
}

Masculinities and training of physical education teachers at EEFD/UFRJ

\author{
Rafael Marques Garcia \\ Doutorando em Educação Física \\ Universidade Federal do Rio de Janeiro, Rio de Janeiro, Brasil \\ rafa.mgarcia@hotmail.com \\ (1) http://orcid.org/0000-0002-0837-1493
}

Erik Giuseppe Barbosa Pereira Doutor em Ciências do Exercício e Esporte Universidade Federal do Rio de Janeiro, Rio de Janeiro, Brasil egiuseppe@eefd.ufri.br

(1) http://orcid.org/0000-0001-8129-4378

A lista completa com informações dos autores está no final do artigo

\section{RESUMO}

A Educação Física enquanto área de conhecimento se fixa e instaura a partir de modelos sexistas, generificados e generificadores, demarcados por diferenças e desigualdades de gênero e (re)produtores dessas diferenças. Este estudo pretendeu compreender a dinâmica de relações entre as masculinidades durante a formação superior de Educação Física. Perguntamos: as várias formas de masculinidades seccionam sujeitos, possibilitam ou renegam direitos e deveres diferentes de acordo com suas performatividades? Para alcançar esse objetivo, nos apropriamos da abordagem qualitativa, de tipo etnográfico, para observar quatro disciplinas obrigatórias, de 60 horas, do curso de Licenciatura em Educação Física durante um período acadêmico. Como resultados, pudemos denotar que as masculinidades próximas da hegemônica contornam homens cis-heterossexuais de maiores possibilidades e poderes, estabelecendo-se em um jogo de hierarquias que ridiculariza, menospreza e objetifica mulheres e outras identidades de gênero e sexualidades, 0 que pode vir a ser replicado durante a atuação profissional desses/as professores/as.

PALAVRAS-CHAVE: Educação Física. Identidade de Gênero. Masculinidades. Orientação Sexual.

\begin{abstract}
Physical Education as an area of knowledge is established based on sexist, gendered and generative models, demarcated by gender differences and inequalities and (re)producer of these differences. This study aimed to understand the dynamics of relationships between masculinities during higher education in Physical Education. We ask: do the various forms of masculinities section subjects, enable or deny different rights and duties according to their performativities? In order to achieve this goal, we use the qualitative approach, of an ethnographic type, to observe four compulsory subjects, of 60 hours, of the Physical Education Degree course during an academic period. As a result, we were able to denote that masculinities close to hegemony circumvent cis-heterosexual men of greater possibilities and powers, establishing themselves in a game of hierarchies that ridicules, disparages and objectifies women and other gender and sexualities identities, which can be replicated during the professional performance of these teachers. KEYWORDS: Physical Education. Gender Identity. Masculinities. Sexual Orientation.
\end{abstract}




\section{INTRODUÇÃO}

As motivações para a realização deste estudo surgem a partir de vivências pessoais do primeiro autor durante sua graduação em Licenciatura em Educação Física na Escola de Educação Física e Desportos da Universidade Federal do Rio de Janeiro (2013-2016). Em vários episódios, por apresentar aspectos de uma masculinidade subalterna ${ }^{1}$, o autor (homem cis-homossexual $^{2}$ ) foi motivo de sátira, gozação e exclusão no momento de formação de grupos para atividades. O cenário nos gerou muita inquietação, uma vez que não recaía exclusivamente a um aluno, mas também a outros/as que não se expressavam de formas hegemônicas. O que exacerbou nossas inquietações foi perceber que estas ações se repetiam constantemente, todos os dias, em variadas disciplinas, nos corredores, nas salas, nas quadras e em cada espaço do prédio de Educação Física com todo/a aquele/a que, de alguma forma, perturbava as normas de gênero e sexualidade.

Estas situações podem refletir o contexto brasileiro de edificação da Educação Física enquanto área de conhecimento, a partir de modelos sexistas, generificados e generificadores, demarcados por diferenças e desigualdades de gênero e (re)produtores dessas diferenças. Essa peculiaridade criou uma identidade à luz de uma matriz biologicista dita natural, que foi e vem sendo cristalizada e cultuada socialmente, estendendo-se, ao que tudo sugere, para o espaço de formação de professores/as na respectiva área (JACO e ALTMANN, 2017).

Entendendo os processos e relações sociais como produtos complexos e históricos das civilizações humanas (PEREIRA et al, 2015), reconhecendo que seria impossível uma mudança tão repentina e drástica de condutas e comportamentos historicamente cristalizados, inclinamos nosso olhar para o processo de formação de professores/as de Educação Física a partir das relações entre as masculinidades. Neste interim, preocupounos o fato de que, por estarmos em uma escola de formação, os eventos supranarrados passavam despercebidos aos olhos alheios, a não ser daqueles/as cujos/as quais eram alvo ou tinham direcionados para si tais impugnações e que, por variadas vezes, nada tinham a fazer ou a quem recorrer.

\footnotetext{
${ }^{1}$ Neste texto, as noções sobre as categorias de masculinidades serão discutidas a partir da ideia inicial de Robert Connell (hoje Raewyn Connell) em seu texto "Políticas da masculinidade" (CONNELL, 1995). Entendemos que as discussões sobre a temática se ampliaram ao longo das duas últimas décadas, mas acreditamos que a Educação Física ainda carece de investigações voltadas a essa primeira elucidação do conceito de masculinidade(s), sendo esta a razão do porquê a estamos utilizando no presente documento.

2 Uma pessoa cis, homem ou mulher, é aquela que se reconhece no sexo/gênero designados em seu nascimento. Caso apresente discordância com algum desses identificadores, a pessoa é denominada trans.
} 
Sobre as discussões e investigações teóricas acerca das masculinidades, destacamos seu sobressalto durante o movimento feminista, em especial ao proporem analisar a dinâmica de relações estabelecida entre homens e mulheres ${ }^{3}$ à luz do patriarcado (CONNELL, 1995). Connell vem, desde a década de 1980, dedicando-se a estudar sobre a construção das masculinidades de acordo com questões de poder, culturais e sociais, que se traduzem em sistemas de vida e de controle com forte assentamento no patriarcado (BRITO e LEITE, 2017). Uma das teorizações mais conhecidas de Connell é sobre a masculinidade hegemônica, construída justamente pela análise do patriarcado nas sociedades ocidentais, denunciando posições de poder e prestígio social diferente entre homens e mulheres, mas também entre os próprios homens, através da subordinação de mulheres e das masculinidades ditas subalternas àquela considerada hegemônica (CONNELL, 1995; BRITO; LEITE, 2017).

As pesquisas sobre masculinidades e Educação Física ${ }^{4}$ se concentram majoritariamente nas análises de modelos próximos ao ideal hegemônico, sendo ainda pouco estudado o processo de resistência e potência subversiva das masculinidades subalternas (PORTILHO; BRITO; SANTOS, 2020). Como importante marco, essas pesquisas caminham agora rumo às perspectivas pós-estruturalistas, que visam questionar "o caráter heterossexual do conceito de gênero, possibilitando o reconhecimento de uma masculinidade e feminilidade 'plurais', contestando a noção de identidades hegemônicas" (DEVIDE et al, 2011, p. 95). Assim, busca-se aumentar as possibilidades de compreensão e análise das diversas formas de se portar masculino nas práticas corporais, esporte e na Educação Física (PORTILHO; BRITO; SANTOS, 2020).

Brito e Leite (2017) e Brito (2018) expõem a classificação das masculinidades, com base em Connell, através de um processo de hierarquias onde aquela considerada hegemônica ocupa o topo da lista, sendo as demais, as subordinadas, consideradas cúmplices, irrompendo daí a própria dinâmica das masculinidades. Sinalizam também que a masculinidade hegemônica é o modelo de aspiração para as demais, por vezes inatingível, mas guiando os processos de construção e reprodução das diversas nuances de masculinidades de acordo com espaços socioculturais diferentes (BRITO; LEITE, 2017).

\footnotetext{
${ }^{3}$ No texto, Connell não especifica a cisgeneridade ou transgeneridade. Todavia, neste caso, a autora está tecendo suas ideias sobre identidades de homens e mulheres cis, identidades possíveis de (sobre)vivência aos corpos dos séculos passados.

${ }^{4}$ Devide et al (2011), em pesquisa bibliográfica sobre os estudos de gênero na Educação Física brasileira, destacam que a área carece de linhas de pesquisa ou projetos que se dediquem a estudar homens e masculinidades especificamente, muito embora já existam produções isoladas sobre a temática em território nacional.
} 
O grande interesse dos homens na masculinidade hegemônica decorre dos privilégios que eles podem dela colher em uma sociedade dita patriarcal, tais como melhores posições de trabalho, melhor faixa salarial, o direito de falar e/ou ditar as dinâmicas sociais, entre outros. Também, marcar-se dentro desse jogo de poder os distancia do elemento de suspeição da masculinidade, muitas vezes remetente à orientação sexual homossexual. Nesta, a masculinidade seria considerada subordinada ao ponto de desqualificar ou não reconhecer a própria identidade do homem não heterossexual, controlada via exclusões, discriminações e ridicularizações (CONNELL, 1995). Aqui, opera a lógica da subordinação das masculinidades, onde se persegue, ofende e ojeriza aquele comportamento que perturba a lógica da heterossexualidade entre os homens.

Cientes desse quadro, esta pesquisa surge com a proposta de compreender a dinâmica de relações entre as masculinidades durante a formação superior de Educação Física, onde nos guiamos pela seguinte questão: as várias formas de masculinidades seccionam sujeitos, possibilitam ou renegam direitos e deveres diferentes de acordo com suas performatividades? Torna-se importante compreender como esses mecanismos são articulados e como contribuem para a formação de professores/as através de adversidades díspares, desacertadas e que podem, por assim desenrolar-se, desfavorecer essa formação acadêmica, ou ainda conduzi-la para outros inúmeros vieses, influenciados por arquétipos sociais variados e infindáveis. À luz de Pereira et al (2015, p. 148), “[...] é fundamental que se questione o modelo que tem servido como parâmetro de referência às atividades ditas femininas ou masculinas".

\section{METODOLOGIA}

Este estudo ${ }^{5,6}$ é de caráter qualitativo e de tipo etnográfico. Gaya (2008) esclarece que o determinante para a adoção metodológica qualitativa é a forma como o pesquisador anseia em retratar e analisar um evento ou problemática. Sob esta gama, o objetivo primário de tal empreitada se encontra ancorado pelo aprofundamento e entendimento de determinadas manifestações sociais através de análises infindáveis da complexa articulação entre sujeitos, fenômenos e sutilezas circunstanciais (como temporalidade, espaços físicos, aspectos socioculturais, biopolíticos, entre outros).

${ }^{5} \mathrm{O}$ presente trabalho foi realizado com apoio da Coordenação de Aperfeiçoamento de Pessoal de Nível Superior - Brasil (CAPES) - Código de Financiamento 001.

${ }^{6}$ Recorte de uma dissertação de mestrado. Aprovado pelo Comitê de Ética em Pesquisa do Hospital Universitário Clementino Fraga Filho (HUCFF/UFRJ), sendo o número do parecer 2.004.957 e o protocolo 039-17, grupo III. 
Molina Neto (2004) explica que, no que se refere à técnica etnográfica, a proposta é identificar e discutir crenças, ideias, sentidos e importância de determinadas práticas dentro de contextos específicos. Embora a etnografia seja uma técnica que se apresente de forma adaptável, não fixa e instável, ela se torna uma importante ferramenta potencializadora da quantidade de interpretações que podem se desenrolar durante os processos de estudo/discussão (MOLINA NETO, 2004), o que realizamos através da técnica de observação.

Desta forma, a transcrição das informações e observações deve-se aproximar-se do mais rico e detalhado possível, a chamada descrição densa (GEERTZ, 1989), onde só então será possível tecer análises múltiplas sobre estruturas significantes e sua correlação com o corpo e as práticas corporais. Neste sentido, Geertz (1989) nos adverte da necessidade de ser cauteloso e reconhecer os limites aos quais se propõe a etnografia, uma vez que esse trato decorre das sensitividades, angústias, anseios e tensões do próprio investigador, materializando assim os limites etnográficos.

Nossos procedimentos metodológicos de observação, seleção e sistematização descritiva dos eventos pautaram-se em observar, registrar e analisar adequadamente nossos achados através das seguintes etapas (MOLINA NETO, 2004): 1- estabelecimento de uma noção de estranhamento dos acontecimentos observados; 2- desenvolvimento de sentidos observacionais conforme a proposta da pesquisa (neste caso, eventos relacionados a masculinidades, gênero e orientação sexual); 3- elaboração e manutenção de diretrizes para observação e registros em um diário de campo; 4- descrição densa de contexto e sujeitos envolvidos nos eventos; 5- olhares atentos para elementos recorrentes, bem como aqueles imprevisíveis e/ou inesperados; 6- delimitação dos eventos, demarcando seu início, desenvolvimento e finalização.

Assim, a partir de nossas inquietações, delineamos alguns apontamentos para nos aproximar tanto do corpo docente quanto discente de maneira que pudéssemos compreender as dimensões envolvidas entre o dito e o não dito, o expressado, o consentido, o silenciado. O primeiro passo foi pensar de que maneira poderíamos contemplar o objetivo desta pesquisa em meio a tantas disciplinas, docentes e discentes que juntos compõem o currículo teórico-prático do curso de Licenciatura em Educação Física.

Após algumas discussões para encontrar denominadores em comum, decidimos nos concentrar nos/as alunos/as devidamente inscritos/as em quatro disciplinas obrigatórias do referido curso, bem como seus/suas respectivos/as docentes. O segundo passo foi 
denominar quais seriam as disciplinas a serem observadas. A escolha seguiu os critérios: 1- a obrigatoriedade de cursar a disciplina; 2- O caráter teórico-prático desta; 3- carga horária total de 60 horas e; 4- distribuição diluída ao longo do curso (sendo uma disciplina recomendada ao $1^{\circ}$ período, uma ao $3^{\circ}$, uma ao $5^{\circ}$ e uma ao $6^{\circ}$ ).

Desta forma, definimos nosso processo de análise para as quatro disciplinas, gravando-as aqui não com seu título fidedigno, mas sim a quais conteúdos se referem: 1Folclore Brasileiro e Danças (FD); 2- Estudos da Capoeira (EC); 3- Estudos do Futebol (EF) e; 4- Estudos do Voleibol (EV).

Antes do início do período letivo, procuramos cada docente responsável pela disciplina e explicamos a pesquisa em si, bem como seus objetivos, procedimentos e justificativas. Após a concordância de cada um/a, entregamos então duas vias do Termo de Consentimento Livre e Esclarecido (TCLE) para ratificar sua anuência e permissão, recolhendo posteriormente uma dessas vias para arquivá-la em nosso material, deixando a sobressalente com o/a próprio/a.

Neste momento, também foi discutido qual seria nossa atuação durante as aulas, com o intuito de não prejudicar em nenhum momento o calendário desenvolvido por cada docente, nem o andamento das aulas, das atividades e/ou dos testes. Também foi informado que não estaríamos avaliando seus métodos de ensino, técnicas de avaliação ou demais condutas de docência não pertinentes ao objeto de nosso estudo. Restringimonos ao papel de observar cada uma das aulas, sem participar ativamente da realização das tarefas, mas podendo interagir com os/as alunos/as caso estes momentos fossem propiciados.

Ao início do período letivo, o mesmo procedimento adotado para com os/as docentes foi repetido aos/às discentes. Certos de seus direitos e do que a pesquisa se tratava, todos/as concordaram em participar via TCLE, onde obtivemos assim um conjunto pleno de assentimento por parte dos/as participantes do estudo.

Compôs nosso conglomerado de atores/atrizes da pesquisa um total de 109 participantes: 4 são docentes (cis), sendo 3 homens e 1 mulher; 4 são monitores (cis) das disciplinas, sendo 2 homens e 2 mulheres; e 101 discentes, sendo 59 homens, 41 mulheres e 1 sujeito transgênero não-binário, distribuídos/as da seguinte maneira:

FD: 1 docente mulher, 1 monitora e 22 discentes, sendo 14 mulheres e 7 homens (todos/as cis) e 1 sujeito transgênero não-binário; EC: 1 docente homem, 1 monitor e 32 discentes, sendo 18 homens e 14 mulheres (todos/as cis); EF: 1 docente homem, 1 
monitora e 20 discentes, sendo 15 homens e 5 mulheres (todos/as cis); EV: 1 docente homem, 1 monitor e 27 discentes, sendo 19 homens e 8 mulheres (todos/as cis).

As aulas então passaram a ser acompanhadas e registradas em um diário de campo ao longo do período acadêmico ao qual foram analisadas (FD: 2017-2; EC e EF: 2017-1; EV: 2015-2). Ao longo de cada um desses períodos, reformulamos nossas técnicas de observação e registro para melhor verificar os fenômenos que nos propusemos a analisar (por exemplo: observar a aula mais de perto ou longe; registrar os dados imediatamente após as aulas ou durante as mesmas; utilizar um notebook para os registros ou o smartphone). Como acordado, em nenhum momento interferimos nas ações ou ritmo das aulas, limitando-nos a assisti-las e interagir com os/as alunos/as caso estes/as solicitassem informações ou buscassem esse contato.

Todo material coletado foi registrado em um diário para cada disciplina, sendo dividido pelos dias em que as aulas e suas ocorrências se manifestaram. Esses conjuntos foram cuidadosamente lidos, relidos e analisados, o que possibilitou a formulação de agrupamento de ideias e/ou inferências que se aproximavam entre si, definindo assim categorias de análise. Cabe frisar que, tão logo algum fenômeno se manifestasse, no ato da descrição já era identificado e sublinhado conforme seu enquadramento a ser tratado, demarcando assim o trato etnográfico.

Para o desenvolvimento da pesquisa de campo, decidimos acompanhar cada uma das aulas ofertadas às turmas tanto em seus momentos teóricos, quanto práticos e/ou avaliativos durante todo o semestre acadêmico, oportunizando-se assim uma maior chance de aproximação com os sujeitos da pesquisa, o que facilitaria nosso trabalho de coleta de dados. Desta forma, admitimos que seria mais interessante processar os acontecimentos de cada dia em cada uma dessas disciplinas do que selecioná-las aleatoriamente, uma vez que ao estabelecer o vínculo da convivência, a presença do pesquisador etnógrafo tornarse-ia, ao longo do tempo, quase que invisível aos olhos dos/as demais (sendo este o momento primordial para o estudo em si, pois os sujeitos agiriam da maneira costumeira, e não melindrados pelo receio ofusco de estar sendo observado para uma pesquisa e passível de julgamento por suas atitudes). Por fim, todas as nossas interpretações foram sistematizadas e tecemos nossas arguições a partir dessas categorizações. 


\section{RESULTADOS E DISCUSSÃO}

Nossos resultados foram agrupados em subitens após análise preliminar, sendo: 3.1 Exclusão; 3.2 Conotações sexuais e; 3.3 Processos fóbicos e ridicularizações. Em cada uma dessas unidades, apresentamos primeiros o bloco e suas cenas mais impactantes (selecionamo-las de nosso vasto material de acordo com o impacto gerado), e, logo em seguida, analisamos o material de acordo com nosso arcabouço teórico.

\subsection{Exclusão}

Cena 1, EF, de 29/03/2017 - Cenário: Ginásio Esportivo (GE)

Foi proposto um aquecimento onde um aluno seria o queimador e teria posse de uma bola, devendo dizer uma cor e tentar encostar a bola em algum colega que vestisse roupas da cor escolhida. Posteriormente, uma nova bola foi inserida, tendo o jogo agora dois queimadores. Nesta dinâmica, a aluna B.B., única mulher presente, buscou afastar-se de onde realizavase a atividade, embora participasse da mesma. Sua presença pareceu ser indiferente aos seus colegas.

\section{Cena 2, EF, de 03/04/2017 - Cenário: Ginásio Esportivo (GE)}

No jogo, a aluna B.B. correu pela quadra, deslocou-se pelos espaços livres e mesmo sem marcação não recebeu nenhum passe de seus colegas. Durante quatro minutos de jogo B.B. não tocou na bola, o que veio a ocorrer quando ela estava próxima do gol e enfim recebeu um passe, no entanto não obteve sucesso na marcação do tento. Os alunos homens passaram a dominar a partida, inclusive com emprego de força física e jogadas perigosas, e C.C., a outra aluna mulher presente na turma, mesmo nas mesmas condições de B.B., também teve participação quase nula na partida. A monitora não se atentou para o fato, tampouco o professor, e o jogo continuou desta maneira. Em determinado momento do jogo, a monitora inseriu-se na aula e em menos de um minuto recebeu três passes de seus colegas na elaboração das jogadas, enquanto B.B. e C.C. continuaram preteridas. No entanto, a participação masculina ainda se mostrou hegemônica.

\section{Cena 3, EF, de 08/05/2017 - Cenário: Ginásio Esportivo (GE)}

No decorrer da aula, a aluna C.O. informou ao professor que não participaria na quadra porque só havia homens jogando, de forma muito aguerrida, e isso a intimidava. $O$ professor disse que poderia procurar uma alternativa, no entanto C.O. enfatizou que não se sentia à vontade em ser a única mulher em quadra, permanecendo fora da aula.

Neste subitem, temos três episódios ocorridos nas aulas de EF que denunciam a ocorrência de mecanismos excludentes aos/às menos/as habilidosos/as, principalmente às mulheres. Cabe refletir de que maneira surge este processo e como ele direciona as práticas pedagógicas ao longo desta disciplina, ainda mais se lembrarmos das peculiaridades socioculturais desse conteúdo em específico - o futebol, consagrado como espaço masculino e de culto à masculinidade hegemônica. 
Connell (1995) reafirma que a construção das masculinidades se dá sobre características inerentes, onde as particularidades mais frágeis e emocionais, entendidas como femininas, configurariam uma imagem deturpada e subversiva de ser e estar masculino. A arquitetura da masculinidade socialmente esperada - hegemônica - é um processo árduo que transforma rapazes em máquinas supressoras de sentimentos e produtoras de brutalidade, trazendo consigo maior descuido com a integridade física e/ou maior exposição a riscos. A estruturação desse modelo androcêntrico desponta como uma necessidade quase que inerente aos rapazes, por vezes cruel e extremamente debilitadora, mas que tenuamente narram as práticas corporais analisadas.

A diferença que se apresenta neste momento não é exclusividade da aula no ensino superior, mas talvez seja o resultado de toda uma construção que tenha se iniciado em outros momentos, inclusive na Educação Física escolar (PRADO, 2014). Como se sabe, "[...] as meninas, muitas vezes acabam tendo participações mais limitadas e menos envolvimento com a educação física escolar" (JACO; ALTMANN, 2017, p. 3). Possivelmente, o envolvimento menor do público feminino nessas atividades, sobretudo no futebol, contribua para que elas assumam posicionamentos distantes de protagonização em alguns momentos. Já em outros, quando tentam se engajar às práticas, são descartadas ou excluídas pelas suas habilidades inferiores quando comparada aos homens que governam estes territórios.

Como já tecido anteriormente, essas diferenças não seriam valências inerentes ao gênero, mas sim (re)produzidas durante processos educacionais e de vivência da própria corporalidade: os homens jogam melhor porque desde crianças sempre foram incitados e libertos para essa prática. Atrelado a este fator, na turma de EF temos uma participação ativa muito maior de homens do que mulheres, até mesmo pelo fato de a classe ser composta mais por eles do que por elas. No entanto, percebe-se que o domínio masculino neste espaço de formação melindra a interação mais efetiva das alunas, como o caso de C.O. e B.B., que variadas vezes se retiram ou se negam a participar devido à truculência de seus colegas ou desestímulo que lhes causam. Ou ainda, um dos motivos que justificaria o distanciamento das alunas, à luz de Altmann (2002) e Prado (2014), seria uma corporificação das normas culturais de gênero, isto é, o reconhecimento de que aquela prática não seria apropriada para seu gênero.

Paradoxalmente, quando a monitora se insere na atividade (cena 2), rapidamente é acionada para participar das jogadas, o que sinaliza outra dedução: por ser habilidosa no futebol, é de interesse de sua equipe que ela tenha participação ativa, mesmo neste 
momento de aprendizado pedagógico. Com isso, podemos perceber uma dissensão, onde o foco principal da aula passa a ser a habilidade física e as táticas de jogo para vencer uma partida recreativa, e os aspectos formativos e didáticos passam a ser desconsiderados. que nos preocupa neste panorama é que, muitas vezes, essas ações possam reforçar a naturalização da exclusão e diferenças de participação entre os gêneros (PRADO; ALTMANN; RIBEIRO, 2016), que poderá futuramente refletir no ato profissional dos/as pesquisados/as.

Conforme nos apontam Altmann (2015), Mariano e Altmann (2016) e Jaco e Altmann (2017), nas aulas de Educação Física escolar, os/as professores/as acabam por reforçar comportamentos, ações e organizações dos/as alunos/as na maioria das vezes concernidos por arranjos heteronormativos ${ }^{7}$ e limitadores da própria corporalidade. Neste sentido, parece existir um ciclo vicioso guardando a Educação Física organizado da seguinte maneira: em seu momento escolar, reforça-se a desigualdade de gênero, as diferenças fisiológicas e as participações desiguais nas atividades; já no ensino superior, ocorre a intensificação destes preceitos e pouco ou nenhuma vez se discute sobre esses aspectos, formando professores/as que atuarão nas escolas recomeçando este ciclo e mantendo essa engrenagem sempre lubrificada.

O ponto significativo desta discussão é a necessidade de se refletir, desafiar e suspeitar dos entendimentos sobre corpo, masculinidades e feminilidades que estão entranhados nos conteúdos de aula e presentes em nossas práticas pedagógicas, objetivando romper com este ciclo e garantir que todos/as possam participar e vivenciar o próprio corpo e suas capacidades, sem exclusões de qualquer ordem. É uma responsabilidade do/a docente formador, mas também do corpo discente em formação, haja vista que existe um transvio das propostas pedagógicas, da parte deste, nos momentos práticos de EF aqui analisados.

\subsection{Conotações sexuais}

Cena 1, EC, de 13/03/2017 - Cenário: Ginásio Esportivo (GE)

No final da aula, o professor reuniu a turma e explicou um pouco mais sobre como seria o curso. Reforçou que os alunos precisam trazer um atestado médico para a prática de atividades físicas e fez um breve comparativo de como era a educação física em sua época e atualmente. Ele chegou a dizer

\footnotetext{
${ }^{7}$ Brito (2018), como um dos autores que se destaca nos estudos de masculinidade e Educação Física, explica que o termo "heteronormatividade" foi desenvolvido pelo crítico literário norte americano Michael Warner para explicar o conjunto de normas sociais e seus dispositivos de enunciação que asseguram a heterossexualidade como único modelo legítimo de orientação sexual. Nessa, busca-se controlar e vigiar o estilo de vidas de sujeitos de acordo com as ideias de uma heterossexualidade reprodutora.
} 
que "antigamente os alunos vinham cursar educação física achando que isso aqui era clube ou para pegar mulher".

Cena 2, EC, de 17/05/2017- Cenário: Ginásio Esportivo (GE)

Mais à frente, os alunos P.D. e S.M. aproximaram-se da parede do ginásio para espiar na estrutura vazada a aula que ocorria na quadra de tênis, ocasião em que o monitor se aproximou e perguntou "Tem mulher gata aí?", observando também a aula da outra turma. Não vislumbrando o que esperava, afastou-se e circulou pelo ginásio enquanto P.D. e S.M. permaneceram por mais alguns segundos observando a aula de tênis para só então retornarem à aula de capoeira.

Cena 3, EC, de 31/05/2017 - Cenário: Ginásio Esportivo (GE)

Ao final, o monitor fez a chamada e o professor deu seus informes finais. No entanto, perdeu-se em conteúdo e passou a relatar fatos que aconteciam na universidade na sua época de aluno. Disse que o consumo de maconha era alto, bem como os roubos dentro dos vestiários. Citou inclusive que algumas alunas roubavam as calcinhas das outras. Os alunos riram da afirmação. $O$ monitor olhou para o aluno C.E. e afirmou: "Pô, roubar calcinha é bonzão!", rindo juntamente do aluno.

\section{Cena 4, EC, de 19/06/2017 - Cenário: Ginásio Esportivo (GE)}

As avaliações seguiram sem grandes acontecimentos. $O$ grupo de alunos que conversava sobre as festas agora passou a conversar sobre sexo e as "garotas que estão comendo". Duas alunas da turma seguinte, que estavam treinando as sequências em uma das extremidades da quadra, se aproximaram do grupo, ocasião em que os alunos S.M. e P.A. abraçaram e beijaram uma delas em função de seu recente aniversário. Ainda, perguntaram sobre festas e churrascos as quais elas iriam e desafiaram-nas a irem em uma determinada festa da faculdade. As alunas, assim como os demais do grupo, riram alto várias vezes. O aluno P.R. começou a acariciar uma das alunas. Todos continuaram rindo, até começarem a comer biscoito e a conversar sobre praia.

\section{Cena 5, EV, de 12/01/2015 - Cenário: Sala de aula (SA)}

O monitor da disciplina ministrou uma aula de caráter teórico que consistia em uma revisão sobre os fundamentos até então estudados e suas abordagens características, bem como a apresentação de vídeos para facilitar a assimilação do conteúdo. Na turma EFB, durante a transmissão dos vídeos, a atleta Camila Brait, líbero da seleção brasileira, realizava um determinado gestual técnico de voleibol e um dos alunos, D.J., ao assistir, comentou com seus colegas próximos: “Gostosa!". Alguns riram, outros não esboçaram reação.

\section{Cena 6, EF, de 17/05/2017 - Cenário: Cenário: Sala de aula (SA)}

Antes de se iniciar a apresentação do grupo $C$, os membros deste grupo enfrentaram dificuldades com os aparelhos de Datashow e o computador. Enquanto tentavam solucionar esse problema, o restante da turma trocou ideias sobre assuntos aleatórios. Num aglomerado composto apenas por homens, C.K. riu enquanto observava algo no celular, despertando a curiosidade de seus colegas. O referido aluno então mostrou o conteúdo do smartphone aos mesmos: era um vídeo pornográfico que continha um casal heterossexual onde a mulher realizava sexo oral no homem e tinha seu rosto filmado pelo mesmo. Os colegas de C.K. também riram, além de apontar à tela do celular quando a mulher olhava para a gravação. Percebendo a 
presença do pesquisador atrás dos mesmos, os alunos logo se contiveram e C.K. rapidamente recolheu o celular.

\section{Cena 7, FD, de 22/08/2017 - Cenário: Ginásio Esportivo (GE)}

Os alunos então formularam duas colunas posicionadas de frente uma à outra, onde deveriam ocorrer várias trocas entre os membros. Uma das colunas foi denominada de cavalheiros, e a outra de damas. Alguns homens do segundo grupamento riram desconfortáveis pela nomenclatura que receberam. Na encenação seguinte, em que os pares tinham de dar as mãos, aproximar e afastar, enlaçar os braços e caminhar, girar por sob o baixo do cavalheiro e repetir tudo novamente, os pares masculinos acabaram rindo várias vezes, principalmente devido à reprodução da dama de maneira vexatória e repleta de trejeitos que ridicularizariam o masculino. A professora exemplificou a atividade com o aluno P.P., ocasião em que a turma exclamou entre risos: "hmmm", "opa", "eeee", "agora sim hein".

\section{Cena 8, FD, de 30/11/2017 - Cenário: Ginásio Esportivo (GE)}

Foi proposto um aquecimento que consistia numa série de alongamentos. Em seguida, a turma foi reorganizada no fundo da sala, ficando de frente aos membros do grupo, que passaram cinco passos básicos do funk. Um dos movimentos consistia de flexionar o quadril, elevando o joelho, ocasião em que a aluna B.P., membro do grupo e direcionadora da atividade, disse: "Meninas, vamos colocar um charminho nisso aí, dá uma reboladinha na hora de subir", remexendo o quadril no momento da flexão. A turma riu timidamente.

Neste subitem, é possível destacar nichos que operam nas ordens de conotação sexual, sendo a objetificação das mulheres por parte dos homens mais uma forma de comprovar e manter a busca por uma masculinidade hegemônica. A análise do primeiro discurso proferido pela cena 1 por si só já denuncia esse viés interpelativo. Entender o espaço da Educação Física como "clube" ou "para pegar mulher" confere a legitimidade para a ocorrência de certos eventos que se sucedem pelas cenas, onde o olhar dos homens às mulheres sempre carrega um misto de desejo, apreciação ou objetificação.

Essa maneira do olhar pode ser compreendida dentro de uma rede de significados que sujeitam às mulheres um estado de objetificação sexual. No universo masculino, um eixo desta ordem parece se ramificar como "normal" ou inerente à sexualidade masculina, que seria inclusive a justificativa para a suposta naturalização de dominação, controle e impulsos sexuais masculinos (SEIDLER, 1987).

Desta forma, para saciar suas pulsões biológicas, inegáveis e incontroláveis, os homens cis-heterossexuais teriam acesso e permissão para explorar sua sexualidade através da objetificação feminina em todo lugar possível, inclusive dentro da sala de aula, assistindo pornografia (cena 6, onde o vídeo reproduzia atos de submissão sexual da mulher, o que divertia os rapazes); trocando comentários sobre mulheres (cena 5, onde a 
atleta perde esse status e passa a ser vista como "gostosa"); conversando sobre seus feitos sexuais com elas e acariciando-as (cena 4, onde os alunos da turma de EC compartilhavam suas experiências íntimas de modo saciável entre si); e até mesmo afirmando que o ato de roubar vestimentas íntimas femininas (cena 3, fala do monitor) seria um bom entretenimento.

Neste sentido, ampliamo-nos à leitura de Butler (2015) para compreendermos os enunciados performativos das masculinidades neste processo contingencial. Butler admite a existência de mensagens que são enunciadas e podem se materializar pelos atos de fala, dando luz ao processo performativo e contingencial. Assumir essas relações implica reconhecer que a linguagem não se concebe apenas como código de transmissão, mas também de disseminação e valoração de certos ideais e anseios. Ao trabalharmos as noções de masculinidade com a ideia de gênero performativo de Butler (2015), aproximamo-nos do que Brito e Leite (2017) sintetizam de forma nítida: refletir sobre as várias formas de conferir sentidos às masculinidades e suas formas de expressão é entender essa compreensão de jogos de disputa complexas entre lógicas estabelecidas e outras ainda subversivas, mas também potentes (BRITO; LEITE, 2017). Nesse sentido, não podemos nos esquecer da potencialidade da reprodução masculina fora da norma, deflagrando as inúmeras formas que as relações de poder se instauram e se constituem através da própria performatividade masculina (BRITO, 2018).

O que disso percebemos é que, no discurso dos alunos homens cis-heterossexuais, alavanca-se o aspecto social da enunciação masculina hegemônica, atribuindo interpretações sobre corpos conforme o que o meio desse contexto sociocultural determina: um desejo pelo corpo feminino que possa ser consumido. Destaca-se a permissividade para uma visão sexualizante, que interpreta as mulheres como objetos sensuais e sexuais, que agradam e promovem disputas e conquistas entre os próprios alunos nos espaços de formação, o que pode reduzir ou melindrar a vivência e experiência delas nas atividades e gerar menos aproveitamento formativo. Para Seidler (1987), esse processo seria a saciedade da necessidade, emocionalidade e dependência da qual homens renunciam para atingir o status de poder de uma masculinidade.

Assim, a estrutura de objetificação feminina retira da mulher sua identidade de sujeito e a desqualifica nas relações sociais e humanas, passando a ser agora um objeto, uma "coisa", usada, descartada, perdendo sua dignidade, integridade e seu direito legítimo de reconhecimento independente. Ocorre, possivelmente, a redução em algumas atividades e 
sua efetiva participação, justamente pelo receio deste tipo de enquadramento, que pode influenciar negativamente na sua formação docente.

Muitas vezes, essas junções fazem parte de uma estrutura histórica patriarcal, envolvendo mecanismos de poder aliados a outros processos que, pela lógica social, são bem valorados e reconhecidos, principalmente em termos políticos, onde as possibilidades de experenciar os elementos da sexualidade, tais quais desejos e prazeres, são sempre sugeridas socialmente (LOURO, 2010).

Neste sentido, reforça-se de maneira (in)consciente a premissa de que o masculino deva ser educado para a superioridade não só física, mas também simbólica. Para sustentar seu papel social de poder, inclusive nos espaços de aprendizagem, os homens abdicam de próprias sensações básicas humanas num exercício de autossabotagem, uma vez que o ideal da masculinidade hegemônica - que requer a sátira das outras masculinidades e a hipersexualização e objetificação de mulheres - configura-se como estressante e terrivelmente frágil no que tange à masculinidade, já que esta, por si só, não seria uma realidade biológica e inerente, mas sim uma gama de comportamentos preditos e desejáveis aos alunos em questão. Pelo exposto, percebemos que o grupo discente de homens se empenha em comprovar uma masculinidade hegemônica ou próxima dela, através do uso da força, da velocidade e da potência (não só física, mas também sexual e simbólica, daí os processos de objetificação e ridicularização).

Sobre a dança trabalhada nas aulas de FD (cena 7) cabe trazer uma reflexão sobre sua prática e seu processo de generificação, já que os aspectos feminilizantes são tratados com deboche e ridicularizados, não apenas no momento em que os homens precisam dar vida à figura da dama, mas também durante a incorporação desta figura em corpos masculinizados. À luz das discussões anteriores, esta performatização faz parte de um arranjo heteronormativo que, neste caso, aciona a homofobia para manter a regulação do gênero e policiar a sexualidade dos alunos (PRADO, 2014). Sendo assim, toda prática, roupa, gesto, movimento ou cores seriam empregados para refirmar ou produzir uma própria expressão do que se considera hegemônico à masculinidade (ANDREOLI, 2010) .

A dança nos espaços de formação, de acordo com o imaginário do corpo discente, carrega consigo representações que marcam o gênero e impõem regulações sobre os corpos no momento do aprender/vivenciar, destacando aspectos graciosos e sensíveis que são imediatamente representados por feminilidades esdrúxulas. Logo, percebemos que os homens, ao performarem-se em damas (quando o fazem, já que o evitam ao máximo), utilizam-se de trejeitos exageradamente vexatórios que indicam, inclusive, a existência de 
hierarquizações do gênero e do poder - o homem cis-heterossexual é/está melhor representado/consolidado que a mulher e/ou o homossexual.

Ainda, temos na cena 8 a aluna B.P. solicitando que suas colegas conferissem mais charme ao rebolar o quadril no momento de realizar os movimentos solicitados, o que corroboraria com a ideia de que o papel da dança seria, de fato, sensualizar seus espectadores. Pela lógica heteronormativa, seria instrumento utilizado pelas mulheres para impressionar os homens e assim serem cortejadas por eles. Ou seja, os movimentos para homens não são os mesmos que os das mulheres, embora componham a mesma atividade (ANDREOLI, 2010). Todo esse embasamento justificaria nos/as futuros/as professores/as, por fim, por quê a dança seria uma atividade sempre quase que atrelada ao feminino e aos comportamentos esperados para este gênero, conforme Goellner (2007) já destacava ao sinalizar o imaginário da existência de atividades consideradas próprias para cada gênero.

No entanto, cabe lembrar que embora esta ordenação seja assim estabelecida, existe a permissividade para que o homem possa se inserir no espaço da dança, desde que siga certo roteiro de atuação: pelo viés do celebrar e da serenidade, com partes intocáveis e posturas alvejáveis (ANDREOLI, 2010).

Em suma, o que fica desta unidade é que a dança possui caráter ímpar e ambíguo na formação acadêmica em Educação Física, muitas vezes atrelada a aspectos sensualizantes e/ou sexualizadores que a reduzem a apenas este registro, em uma espécie de idiossincrasia imutável.

\subsection{Processos fóbicos e ridicularizações}

Cena 1, EC, de 20/03/2017 - Cenário: Ginásio Esportivo (GE)

O monitor explicou que os alunos teriam que treinar as esquivas. Disse que não tem como se aprender nenhum movimento sem treinar com seu colega. Em sua fala, ele disse: "Imagina alguém treinando judô sozinho, fazendo os golpes sozinhos, o que ia parecer né? Os outros iriam pensar que né..." (neste instante, o monitor elevou um lado do quadril e "afrouxou os punhos", fazendo uma expressão de espanto ridicularizada e simulando supostos trejeitos homossexuais). Imediatamente após, afirmou: "To zoando!". A turma não manifestou qualquer reação imediata.

\section{Cena 2, EC, de 08/05/2017 - Cenário: Ginásio Esportivo (GE)}

No final da aula, o professor falou sobre os golpes de rasteira. Nessa sessão, solicitou que o aluno P.D. participasse juntamente do aluno voluntário na demonstração. P.D. foi agarrado pelas costas de modo que os braços do aluno voluntário passassem por debaixo de seus braços e se fixassem no pescoço, deixando o corpo de ambos muito próximos. O grupo de colegas composto por S.M., P.A., P.T. e R.N. gargalhou. S.M. sugeriu entre risos que o aluno voluntário desse um beijinho no cangote de P.D. Este mostrou-se visivelmente incomodado. Ainda, colocou seus braços para trás 
de modo que as mãos cobrissem as nádegas, arrancando mais gargalhadas de seus colegas. O suposto contato homoafetivo sugerido pelos colegas foi motivo de chacota e muitos risos. O professor nada fez.

\section{Cena 3, EV, de 17/11/2015 - Cenário: Ginásio Esportivo (GE)}

Durante a realização do pique-cola na turma EFC, um aluno de Licenciatura em Dança, V.O., declaradamente homossexual e cursante da disciplina por livre opção, ao receber a notícia de que um determinado aluno seria o pegador, deixou escapar um leve comentário: "Hm, o pegador...", suspirando em seguida. Neste momento, tanto alunos homens como mulheres se entreolharam, deixando escapar comentários como: "Gente, mas é assim, é?", "Nossa, na cara dura...", entre outros, e apresentando diversas manifestações corporais que variaram desde risos a olhares maliciosos, além de cochichos inaudíveis.

\section{Cena 4, EV, de 23/02/2016 - Cenário: Ginásio Esportiva (GE)}

Na última atividade da aula em EFB, realizou-se um minijogo, marcado pela descontração da turma. Sem se preocupar muito com a técnica, os alunos passaram a realizar os movimentos de forma "relaxada" e descontraída, divertindo-se com os erros dos demais e marcações de pontos tantos a seu favor como contra. Neste contexto, o aluno D.J. chegou a caçoar de J.A. após determinado gesto, dizendo "É muito viadinho...". Dito através de risos, gerou mais risos dos demais.

\section{Cena 5, EF, de 31/05/2017 - Cenário: Ginásio Esportivo (GE)}

Antes do início da partida, os alunos estavam reunidos próximos ao professor conversando sobre o jogo, quando o aluno C.K. perguntou se poderia jogar descalço, pois havia vindo para a aula de chinelo. O professor pediu para ver a sola do pé do aluno, que a mostrou, e depois disso o professor, através de gozações, começou a afirmar ao aluno que ele "não pode jogar descalço bebê, vai machucar o pézinho, lembra da criação com algodão e coca cola? Se plantar um feijãozinho nasce, não pode jogar descalço, vai machucar bebê". Os alunos no entorno riram e provocaram C.K. sob esses aspectos, que rindo, desvencilhou-se dos comentários: "Ah, sai daí, nada a vê", frase repetida enquanto os demais lhe importunavam.

\section{Cena 6, FD, de 07/11/2017 - Cenário: Ginásio Esportivo (GE)}

Um dos temas abordados foi determinismo biológico. Nessa sessão, I.A. levantou questionamentos sobre esse conceito, expondo sua identidade pessoal: disse estar passando por um processo de reconhecimento enquanto sujeito transgênero não-binário, destacando como as atividades ao longo do semestre na disciplina trabalhavam muito com recortes generificados, vindo a dificultar, mas também ampliar, suas ações enquanto sujeito identitário. A aluna J.G., enquanto I.A. expunha sua fala, olhou para sua colega P.V. e cochichou, com feição de deboche: "O que é isso que ele é? Aff...", rindo em seguida. P.V. apenas balançou a cabeça negativamente, consentindo com J.G. A professora ponderou sobre a colocação de I.A., trazendo reflexões sobre a naturalização de certos artifícios ao longo do tempo, entre culturas e sociedades.

Neste grupo, fica notoriamente presente discursos que pressupõem e ridicularizam determinadas ações e pessoas conforme uma lógica linear de expectativas, novamente gravada por ideais de uma masculinidade hegemônica. Corroborando com Rosa (2004) e 
Prado (2014), percebemos a conotação negativa que a homossexualidade carrega no universo da Educação Física. Rosa (2004), ao analisar a formação de professores de Educação Física, identifica duas facetas pelas quais a homofobia materializa essa denotação no espaço universitário: 1- veladamente, onde ocorre o distanciamento de homossexuais supostos ou declarados das atividades, e; 2- transfigurada em brincadeiras e/ou dizeres pejorativos/ridicularizantes - o que aqui fica mais que evidente.

Quando a linearidade de condutas e padrões da masculinidade hegemônica é tensionada, apresenta rupturas ou não é almejada, surge a sátira e a zombaria para destacar o caráter abjeto dos sujeitos referência (PRADO, 2014). Assim, como podemos denotar, as masculinidades subalternas são insignificantes, desvalorizadas e deslegitimadas; de acordo com Brito (2018), as masculinidades que desviam da norma encontram-se em alta condição de vulnerabilidade.

Para entender como se dá esse projeto de abjeção e alta condição de vulnerabilidade, reportamo-nos a Butler (2011), que discorre sobre o caráter de constituição desse "não sujeito" através da corporificação de significados que o fariam ocupar espaços inóspitos e inabitáveis de acordo com determinada cultura. Esse espaço seria, portanto, ojerizado, bem como todos/as aqueles/as que ali foram enquadrados (BUTLER, 2011).

Podemos perceber que os seres abjetos são aqueles que não possuem garantidos, por exemplo, seu direito básico de (sobre)vivência e uso do corpo da maneira como gostariam de ter. Sempre coagidos por normas, os corpos precisam ser encaixotados e tornam-se refém dessas amarras, sob a ameaça de sofrerem com os mecanismos mantenedores desta matriz dominante (como a própria homofobia, por exemplo).

A abjeção de um sujeito deslegitima seu reconhecimento como humano, passando ele a ter agora uma maior precarização de sua identificação, isto é, uma alta vulnerabilidade. Pelas vias cis-heteronormativas, a construção do gênero e da sexualidade se dá por meios excludentes, de apagamentos e articulações que operam nessa produção de acordo com os modelos considerados válidos, e que necessitam de seu opositor obrigatoriamente, para assim estabelecer as identificações de modo hierárquico e desigual - o humano, inumano, menos humano, etc. (BUTLER, 2011). Logo, um exercício da própria noção performativa da masculinidade hegemônica (ou em busca dela) seria não apenas menosprezar outras masculinidades, mas reduzi-las a tal ponto que seriam interpretadas como grotescas, ridículas e passíveis de extermínio social.

Destarte, decorre dos atos performativos e encontra-se intimamente atrelado ao processo de abjeção a própria noção de precariedade maximizada do corpo. Segundo 
Butler (2017), a performatividade também se configura como um fazer de liberdade pública que traz consigo riscos e ameaças por submeter um sujeito às condições de precariedade variantes, fato este que ocorre sempre que alguém expõe os "desvios" de gênero, sexualidade e/ou uso material/simbólico do corpo. Desta forma, configura-se assim seu caráter de abjeção, do não reconhecimento de sua igual importância ou condição humana, isto é, uma vulnerabilidade de vida (física ou simbólica) maximizada.

Como exposto, temos nas cenas desta unidade notáveis sátiras e ridicularizações que ocorrem à figura e/ou ideais sobre homossexuais e/ou sujeitos não heterossexuais homens. Ao se insinuar esta condição os/as protagonistas dos eventos se apropriam de discursos e elementos performativos jocosos, pejorativos e inferiorizantes que de certa forma abjetificam as pessoas ou suas performatividades fora da suposta identidade de gênero e orientação sexual cis-heterossexuais.

Se nos atentarmos para as cenas, podemos perceber certo grau de imaturidade de alguns discentes - homens - com as propostas de vivência corporal que são promovidas (mais uma vez, debochar ou satirizar do colega acaba se tornando o foco principal dos exercícios, onde a gozação instaura os padrões de consolidação entre o permitido ou não para aquela pessoa conforme seu gênero ou sexualidade). Na cena 2, onde o toque entre homens se materializa, percebemos uma dinâmica do tabu (ROSA, 2004), sendo algumas partes consideradas mais intocáveis que outras, como nádegas, mãos e rosto. Amplificando, em nossa sociedade não existe qualquer toque entre homens que esteja dissociado da condição de homossexualidade (ROSA, 2004), estratégia acionada pela turma durante a execução da respectiva tarefa.

Para finalizar, vamos de acordo a Altmann (2015) ao apontar que as cenas desse bloco sugerem ações que consagram ou desgraçam atitudes masculinas dentro deste universo de normas ou ideias coercitivas, instalando precariedades maximizadas durante 0 momento de formação de professores.

\section{CONSIDERAÇÕES FINAIS}

Nas entrelinhas, nossos apontamentos indicam que, embora as performatividades masculinas se apresentam de maneiras alternativas e/ou "diferentes", são também produtos de um modelo classificador da Educação Física, reproduzindo padrões aceitos para os fundamentos de cada modalidade pesquisada de acordo com os ideais da 
masculinidade hegemônica e as identidades de gênero e orientação sexual cisheterossexuais.

A (re)produção performativa das masculinidades foi incessantemente (re)afirmada, especialmente por homens cis-heterossexuais, na formação acadêmica à luz de uma aspiração ao modelo mais hegemônico, assim como os atributos desta qualificação, o que acionou e legitimou discursos homofóbicos, discriminatórios e excludentes, ainda que velados, tanto do corpo discente quanto docente. Pouco se problematizou sobre a temática de gênero, masculinidades e feminilidades no momento de formação pedagógica, a não ser em algumas cenas da disciplina de FD, enquanto que nas demais disciplinas, pelos eventos destacados, essa sinalização díspar entre homens e mulheres, e também entre os próprios homens (todos/as cis), foi ainda mais reforçada.

Pudemos inferir que os discursos de formação em Educação Física já institucionalizados e acionados no momento de construção educativa normatizaram e naturalizaram as condutas e comportamentos do campo de acordo com representações da masculinidade hegemônica, trazendo aspectos sexistas e excludentes. A pouca problematização existente, talvez, não tenha sido suficiente para suscitar questionamentos inquietantes nos/as futuros/as educadores/as de como planejarão suas práticas docentes sob a lógica de gênero, práticas corporais masculinas e femininas, segregações e preconceitos, bem como suas consequências e potências de interlocução e subversão.

Todos esses processos que puderam ser observados, entendidos como elementos simbólicos e que produzem significados de compreensão em contextos socioculturais variados, contribuíram para ratificar as normas sociais que se interpõem sobre os corpos e os gêneros, em especial às noções de masculinidades hegemônica e subalternas, naturalizando assim condutas e comportamentos que possivelmente continuarão retroalimentando os círculos/ciclos viciosos da Educação Física, de fabricar sujeitos não comprometidos com mudanças sociais ou políticas no que concerne à temática em tela.

Como limitações, reconhecemos que a pesquisa é geograficamente pontual, analisando os eventos de um único curso de formação e avançando pouco nas análises de subversão e tensionamento promovidos pelas formas subalternas de masculinidade (impulsionados pelas últimas décadas). No entanto, acreditamos que evidenciar o quadro em tela possa contribuir para que novas ações didático-pedagógicos possam ser (re)pensadas para ressignificar os próprios processos metodológicos da Educação Física no ensino superior e no espaço escolar, sendo essa nossa principal recomendação. 


\section{REFERÊNCIAS}

ALTMANN, Helena. Educação física escolar: relações de gênero em jogo. São Paulo: Cortez, 2015.

ALTMANN, Helena. Exclusão nos esportes sob um enfoque de gênero. Motus Corporis, v. 9, n. 1, p. 9-20, 2002.

ANDREOLI, Giuliano Souza. Dança, gênero e sexualidade: um olhar cultural. Conjectura, v. 15, n. 1, p. 107-118, jan./abr. 2010.

BRITO, Leandro Teófilo de; LEITE, Miriam. Sobre masculinidades na Educação Física escolar: questões teóricas, horizontes políticos. Práxis Educativa, v. 12, n. 2, p. 481-500, 2017.

BRITO, Leandro Teófilo de. Enunciações de masculinidade em narrativas de jovens atletas de voleibol: leituras em horizonte queer. 225p. Doutorado (Programa de PósGraduação em Educação) - Faculdade de Educação da Universidade do Estado do Rio de Janeiro, Rio de Janeiro, RJ, Brasil.

BUTLER, Judith. Alianças queer e política anti-guerra. Bagoas - Estudos Gays: gênero e sexualidades, v. 11, n. 16, p. 29-49, jan./jun. 2017.

BUTLER, Judith. Bodies that matter: on the discursive limits of sex. Londres: Routledge, 2011. 256p.

BUTLER, Judith. Problemas de gênero: feminismo e subversão da identidade. 8. ed. Rio de Janeiro: Civilização Brasileira. Col. Sujeito \& História. 2015.

CONNELL, Robert W. Políticas da masculinidade. Educação e Realidade, v. 20, n. 2, p. 184-206, 1995.

DEVIDE, Fabiano Pries et al. Estudos de gênero na Educação Física Brasileira. Motriz, Rio Claro, v. 17 n. 1 p. 93-103, jan./mar. 2011.

GAYA, Adroaldo (Org.). Ciências do movimento humano: introdução à metodologia da pesquisa. Porto Alegre: Artmed, 2008.

GEERTZ, Clifford. A interpretação das culturas. Rio de Janeiro: LTC, 1989.

GOELLNER, Silvana Vilodre. Feminismos, mulheres e esportes: questões epistemológicas sobre o fazer historiográfico. Movimento, v. 13, n. 2, p. 171-196, mai./ago., 2007.

JACO, Juliana Fagundes; ALTMANN, Helena. Significados e expectativas de gênero: olhares sobre a participação nas aulas de educação física. Educação em foco, v. 22, n. 1, p. 1-26, jun. 2017.

LOURO, Guacira Lopes. Pedagogias da sexualidade. In: LOURO, Guacira Lopes. (orgs). O corpo educado: pedagogias da sexualidade. 3a. ed. Belo Horizonte: Autêntica, 2010. p. 7-35. 
MARIANO, Marina; ALTMANN, Helena. Educação Física na Educação Infantil: educando crianças ou meninos e meninas? Cadernos Pagu, n. 46, p. 411-438, jan./abr. 2016.

MOLINA NETO, Vicente. Etnografia: uma opção metodológica para alguns problemas de investigação no âmbito da Educação Física. In: MOLINA NETO, Vicente; TRIVIÑOS, Augusto Nibaldo Silva (orgs.). A pesquisa qualitativa em educação física: alternativas metodológicas. Porto Alegre: Editora da UFRGS, 2004.

PRADO, Vagner Matias. Entre ditos e não ditos: a marcação social de diferenças de gênero e sexualidade por intermédio das práticas escolares da Educação Física. 2014. 258f. Tese (Doutorado em Educação) - Universidade Estadual Paulista Júlio de Mesquita Filho, Faculdade de Ciências e Tecnologia, 2014.

PEREIRA, Erik Giuseppe Barbosa et al. Os estudos de gênero e masculinidade e seus reflexos para a Educação Física. Revista Brasileira de Ciência e Movimento, v. 23, n. 1, p. 146-156, 2015.

PORTILHO, João Gabriel Marques; BRITO, Leandro Teófilo de; SANTOS, Ana Paula da Silva. Produção acadêmica sobre masculinidades nos anais do congresso brasileiro/internacional de ciências do esporte. Motrivivência, Florianópolis, v. 32, n. 63, p. 1-21, jul./dez. 2020.

PRADO, Vagner Matias do; ALTMANN, Helena; RIBEIRO, Arilda Ines Miranda. Condutas naturalizadas na educação física: uma questão de gênero? Currículo sem Fronteiras, v. 16, n. 1, p. 59-77, jan./abr. 2016.

ROSA, Marcelo Victor. Educação Física e homossexualidade: investigando as representações sociais dos estudantes do Centro de Desportos/UFSC. $131 \mathrm{f}$. Dissertação (Mestrado em Educação Física). Universidade Federal de Santa Catarina. Centro de Desportos. Florianópolis. 2004.

SEIDLER, Victor J. Reason, desire, and male sexuality. In: The Cultural Construction of Sexuality (P. Caplan, ed.), London/New York: Routledge, 1987. p. 82-112.

\section{NOTAS}

Rafael Marques Garcia

Doutorando em Educação Física pela EEFD/UFRJ

Universidade Federal do Rio de Janeiro, Departamento de Jogos, Rio de Janeiro, Brasil

rafa.mgarcia@hotmail.com

(1) http://orcid.org/0000-0002-0837-1493

Erik Giuseppe Barbosa Pereira

Doutor em Ciências do Exercício e Esporte pela UERJ (2015)

Universidade Federal do Rio de Janeiro, Departamento de Jogos, Rio de Janeiro, Brasil

egiuseppe@eefd.ufri.br

(1) http://orcid.org/0000-0001-8129-4378

Endereço de correspondência do principal autor

Av. Carlos Chagas Filho, 540 - Cidade Universitária da Universidade Federal do Rio de Janeiro, Rio de Janeiro - RJ, 21941-599 


\section{CONTRIBUIÇÃO DE AUTORIA}

Concepção e elaboração do manuscrito: R. M. Garcia, E. G. B. Pereira

Coleta de dados: R. M. Garcia

Análise de dados: R. M. Garcia

Discussão dos resultados: R. M. Garcia

Revisão e aprovação: R. M. Garcia, E. G. B. Pereira

\section{CONJUNTO DE DADOS DE PESQUISA}

O conjunto de dados que dá suporte aos resultados deste estudo não está disponível publicamente.

\section{FINANCIAMENTO}

Coordenação de Aperfeiçoamento de Pessoal de Nível Superior - Brasil (CAPES) - Código de Financiamento 001

\section{CONSENTIMENTO DE USO DE IMAGEM}

Não se aplica

\section{APROVAÇÃO DE COMITÊ DE ÉTICA EM PESQUISA}

Aprovado pelo Comitê de Ética em Pesquisa do Hospital Universitário Clementino Fraga Filho (HUCFF/UFRJ), sendo o número do parecer 2.004.957 e o protocolo 039-17, grupo III.

\section{CONFLITO DE INTERESSES}

Não se aplica.

LICENÇA DE USO - uso exclusivo da revista

Os autores cedem à Revista Internacional Interdisciplinar INTERthesis os direitos exclusivos de primeira publicação, com o trabalho simultaneamente licenciado sob a Licença Creative Commons Attribution (CC BY) 4.0 International. Estra licença permite que terceiros remixem, adaptem e criem a partir do trabalho publicado, atribuindo o devido crédito de autoria e publicação inicial neste periódico. Os autores têm autorização para assumir contratos adicionais separadamente, para distribuição não exclusiva da versão do trabalho publicada neste periódico (ex.: publicar em repositório institucional, em site pessoal, publicar uma tradução, ou como capítulo de livro), com reconhecimento de autoria e publicação inicial neste periódico.

PUBLISHER - uso exclusivo da revista

Universidade Federal de Santa Catarina. Programa de Pós-graduação Interdisciplinar em Ciências Humanas. Publicação no Portal de Periódicos UFSC. As ideias expressadas neste artigo são de responsabilidade de seus autores, não representando, necessariamente, a opinião dos editores ou da universidade.

EDITORES - uso exclusivo da revista

Javier Ignacio Vernal, Silmara Cimbalista e Selvino José Assmann (In Memoriam).

EDITOR ASSISTENTE: Eixo temático: (Re)discutindo sexualidade: corpo, prazer e desejo em tempos conservadores

Luiz Barp

HISTÓRICO - uso exclusivo da revista

Recebido em: 17-03-2020 - Aprovado em: 23-04-2021 - Publicado em: 30-04-2021 